\title{
Two Ways to Wellness: Writing as a Means of Self Discovery
}

\section{Kate Jones}

I $t$ is an imperative that individuals strive to find mean ing in self. We need to know who we are and what we can become. One path we may choose to understand our reality involves observing, sorting and constructing our experiences through journal writing. Another path that leads to self-discovery is through recognizing our personal values, skills and behaviours. Here then are two of my favourite ways to work towards wellness.

I became interested in journal writing as a means to self-discovery when I was working on my Master of Education degree in the late 1990's. Numerous studies confirmed journal writing as a positive means to shape a student's unique world. I wanted to check it out for myself.

I facilitated a journal writing class twice in a six-day cycle for six weeks with a unique group of Grade 8 students from Fletcher's Creek Senior Public School Choir in Brampton, Ontario. They had competed and won the role as one of the children's choirs in Andrew Lloyd Webber's production of "Joseph and the Amazing Technicolor Dreamcoat". In theory, the experience of keeping a journal while attending classes and rehearsals for six weeks would help the choristers learn more about themselves as they coped with rehearsal schedules, academ- ics, family and peers. It was my job to "put theory into practice."

Philosophically, journal writing provides a vehicle for students to synthesize information, and make connections between their experiences and the subject matter, thus integrating the curriculum with their own lives. They accept, reject, and redraft their reflective thoughts. Through expressive writing, students construct meaning, thus allowing for individual differ-

Philosophically, journal writing provides a vehicle for students to synthesize information, and make connections between their experiences and the subject matter, thus integrating the curriculum with their own lives.

ences in understanding the same subject matter. Writing from their own experiences, students discover themselves as a distinctive "work of art".

Practically speaking, how do you get students to keep a reflective record of their experiences? Here's what I did, in order of difficulty.

First I launched the idea of journal writing as an informal, expressive way of writing to record thoughts and feelings without concern for grading. They knew that I would be reading their journals, but were reassured that this exercise was about their responses to life's events. Later Shanelle would disclose that she used journal writing to "vent...my feelings", and Harpreet said, "When I am bottled up I have this journal to talk to".

The second task involved providing a list of general topics for them. Themes included: exploration of feelings, observations during rehearsals, description of people connected to the musical, family adjustments and school adjustments. When Tina described the experience of having the judges name the winning choirs she concluded with, "that was probably my happiest three minutes of my life. I looked around and found tears, which belonged to disappointed faces, and tears of happiness."

The third undertaking was to encourage them to focus on specific subjects to help them become critical thinkers. An example: think about who did what on stage and off stage and why? One student described specific traits and physical characteristics about a coach and then asked, "now tell me if I'm wrong but pregnant ladies shouldn't be jumping around should they?"

The fourth activity involved encouraging the choristers to think logically, thus demonstrating their understanding and mastery of experiences. When they discussed journal entries that focused on frustration with fussy coaches, they collectively realized the necessity for perfecting their performance. After this group illustration of rational thought, individual students also displayed logical thinking in their entries. Harleen, for ex- 
ample, realized that one day's silly slip-ups made the coach angry because "the performance is almost coming, and people are still fooling and making mistakes...time for me to start practicing at home, and get it down for good!"

The fifth task was to motivate the students to write daily for ten minutes so they would have a record of self-discovery throughout this amazing time. While they complained about fatigue and work, they tried. After writing four pages of narrative, interspersed with descriptions, feelings and realization of personal growth, Allecia wrote, "I really didn't feel like writing today but I tried to write one paragraph and my pen took over!"

The sixth undertaking for me was to write responses to their entries, thus creating a dialogue between us. It allows the facilitator to take on the role of mentor, supporting, advising, and guiding the writer as needed. Sometimes a simple question in the margin of their journal, such as "I wonder why you would have a fidget contest where you couldn't move for one minute?" would cause them to think more clearly and discover something more about themselves.

The seventh commission was to listen to their concerns and decide when and how to respond sensitively, and talk with the students, either individually or ingroup discussions. For example, when many disclosed fears of opening night anxiety they were asked to describe that night as fully as they could imagine in their journals. They then discussed their entries, laughed at some of their outrageous fears, and requested some deep breathing, visualization and relaxation exercises to calm their jitters.

Gaining their confidence by following their lead was the eighth task. The real job is to not to influence their entries. For example, I did not prompt them to discuss anxieties, but Tina felt confident in disclosing her difficulties trying to fit in to the normal classroom while participating in this wonderful opportunity. The group resolved that their choir was now like a class and the journal writing seminars provided them with a safe place to discuss their issues.

Finally, I wanted to lead the students towards self-discovery, a place of wellness. Teachers can help students feel good about themselves by providing them with opportunities to share, to interact, and to relive their experiences through reading journal entries to one another. Journal writing is a means to wellness where students realize their own value, and that of others.

There are also studies indicating journal writing helps people heal and rebuild their lives. Through workshops for mental health clients, as well as their caretakers, I have found that journal writing can help lead them to wellness.

As a professional facilitator, I have explored another way to help people understand themselves better and feel good about who they are through learning about the strengths of their personality. There are many self-assessment surveys available, but the one I like, partly because it has been designed, researched and introduced by a Canadian firm, is Personality Dimensions ${ }^{\mathrm{TM}}-$ an updated version of True Colors ${ }^{\mathrm{TM}}$. I continue to run workshops based on temperament for a variety of groups, such as teachers, office workers, entrepreneurs, and students from elementary level through to university level.

Since the days of Hippocrates scholars have studied people's behaviours. Their research has consistently confirmed that there are four basic temperament types that tell us "why" we behave in specific ways, what motivates us, and what stresses us out. Personality Dimensions ${ }^{\mathrm{TM}}$ is based on these findings and I have used this tool to guide both students and adults towards a clearer understanding of their preferences. I continue to run workshops based on temperament for a variety of groups, such as teachers, business people, and students from elementary level through to university level.

Learning about temperaments leads people down the path of self-awareness. They recognize that everyone is "hard wired" with specific strengths. Armed with this knowledge they can then balance other temperaments in the classroom, in the workplace, and at home. Understanding how each distinct temperament behaves can lead to improved communications better relationships, which helps everyone in their wellness journey.

While learning the four basic behavioural groups is worthwhile, it becomes even more meaningful if applied in specific situations. For example, teachers find this information relevant when creating a classroom environment to meet the needs of all four groups, or by developing different ways of instructing, or by using a variety of evaluation methods. Career counsellors can help clients by exploring the jobs 
that people in these four groups tend to gravitate towards. Parents can help their offspring reach their potential by understanding specific personality strengths.

In any given group of people there is usually stress, some of which can be alleviated through knowledge of why certain people behave in specific patterns. Let's take a look at how this works.

The director of a small staff in a national, non-profit organization divulged that her team experienced a lot of stress. She disclosed that individually the people were great but as a group there were some concerns. Many of the team members fell into the temperament group that enjoys a lot of interaction in order to build the "family atmosphere" at work. On the other hand, the director and a couple of other staff members fell into a very different temperament group, which prefers quiet time for thinking. During the workshop, when given a task to work on in their respective groups the first group chatted non-stop, while the second group went about getting the job done with little conversation.

The de-briefing session led to a discussion about the differences between these two groups. When asked how the two groups functioned in staff meetings, the participants experienced one of those "aha" moments. Usually, they disclosed, as the various agenda points were raised, the first group liked to discuss them, while the second group preferred some quiet time to think before responding. No wonder the staff meetings stressed everyone out! We put in an action plan for the next staff meeting. First of all, the director agreed to circulate an agenda at least one day before the meeting. This would allow the first group to chat with one another beforehand while providing individual thinking time for the second group. During the staff meeting, the first group agreed that they would then chat less, while the second group agreed that they would consider the points beforehand so they would be ready to discuss the issues during the meeting. In a follow-up telephone conversation with the director, she indicated that the staff meetings were much improved. They were on their way to wellness.

When we apply our knowledge of the four groups to improve communication it is amazing how well we can get along. This next illustration is with a group of teachers, but it applies to business people, hospital staff, families, friends, etc.

One group of teachers stated that they liked policies and stepby-step procedures communicated to them. In the classroom they wanted to give very specific, detailed instructions to their students. In other words they wanted to define "how" to do things. A second group of teachers disclosed that they did not particularly like policies or step-bystep procedures; they preferred more freedom in problem solving.

When asked how each group could apply this knowledge about one another when communicating, say in the classroom, they began looking at the responses of the other group.

A teacher in the first group acknowledged that it had not occurred to him that students falling in the second group would not want to know "how" but needed to know "what" they had to do, and would provide them with opportunities to decide for themselves how they would solve the task at hand. A staff member in the second group said that she would be less annoyed with the students that fell in the first group who seemed to always want to know exactly "how" to approach an assignment and provide them with more details. In other words, it is not about changing the other person, but about accommodating his/her innate needs when communicating - something we all could practice on the road to wellness!

As I continue to run workshops for schools, hospitals, businesses, and the Canadian Mental Health Association it has become clear that both pathways can help people discover the meaning of their activities as they share experiences with one another and explore two ways to wellness.

Kate Jones, M.Ed., is founder and owner of Kate Jones \& Associates, a training and consulting company dedicated to empower groups and individuals with

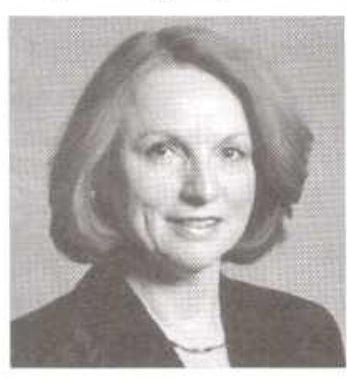
knowledge that enables them to successfully meet many of t o d a y's challenges, in c luding stress, change and work/life balance. Prior to opening her own business, Kate worked in public relations, education, and human resources. Kate's book, Her Journey: Stories of Entrepreneurs is available through her website. Kate's experience, research and dedication guarantee a highly enjoyable and immensely practical learning experience. You may contact her through her website, www.skills4people.com. 